Article

\title{
Evaluation of Accelerated Ageing Tests for Metallic and Non-Metallic Graffiti Paints Applied to Stone
}

\author{
Patricia Sanmartín ${ }^{1, *}$ (D) and Francesca Cappitelli ${ }^{2}$ \\ 1 Departamento de Edafoloxía e Química Agrícola, Facultade de Farmacia, Universidade de Santiago de \\ Compostela, 15782 Santiago de Compostela, Spain \\ 2 Dipartimento di Scienze per gli Alimenti, la Nutrizione e l'Ambiente-DeFENS, Università degli Studi di \\ Milano, Via Celoria 2, 20133 Milano, Italy; francesca.cappitelli@unimi.it \\ * Correspondence: patricia.sanmartin@usc.es; Tel.: +34-881-814-984
}

Academic Editor: Mariateresa Lettieri

Received: 22 September 2017; Accepted: 27 October 2017; Published: 30 October 2017

\begin{abstract}
Graffiti are increasingly observed on urban and peri-urban buildings and their removal requires a huge financial outlay by local governments and agencies. Graffiti are not usually removed immediately, but rather over the passage of time, viz. months or even years. In this study, which forms part of a wider research project on graffiti removal, different methods (gravimetric analysis, examination of digital images, colour and infrared measurements) were used to evaluate the performance of accelerated ageing tests (involving exposure to humidity, freeze-thawing cycles and $\mathrm{NaCl}$ and $\mathrm{Na}_{2} \mathrm{SO}_{4}$ salts) for graffiti painted on stone. Silver (metallic) and black (non-metallic) graffiti spray paints were applied to two types of igneous rock (granite and rhyolitic ignimbrite) and one sedimentary rock (fossiliferous limestone, i.e., biocalcarenite). The metallic and non-metallic graffiti spray paints acted differently on the stone surfaces, both chemically and physically. Older graffiti were found to be more vulnerable to weathering agents. The ageing test with $\mathrm{NaCl}$ and particularly $\mathrm{Na}_{2} \mathrm{SO}_{4}$, both applied to granite, proved the most severe on the paints, yielding more detrimental and faster artificial ageing of the type of material under study.
\end{abstract}

Keywords: accelerated ageing tests; graffiti; coating; stone protection; gravimetric analysis; colour measurements; infrared spectroscopy

\section{Introduction}

Graffiti first emerged in New York in the late 1960s, peaking in the 1970s and becoming popular in Europe in the 1990s. Anti-graffiti campaigns began in the 1980s with new legislation and restrictions. Graffiti vandalism is currently a widespread and costly problem. Removal of graffiti requires a major financial outlay by municipalities and other responsible institutions. The city of Santiago de Compostela (Galicia, NW Spain) spends more money on cleaning graffiti than any of the other cities in this autonomous region; e.g., in 2008, more than 150,000 euros were spent on removing graffiti from the city's buildings [1]. Due to the substantial financial outlay required, removal of graffiti usually does not take place immediately, but over months or even years.

Studies to determine the durability and weathering of graffiti over time are required. However, although anti-graffiti protective coatings have been subjected to weathering tests in many studies (e.g., [2-4]); to our knowledge, the same has not yet been done for graffiti spray paint.

The first accelerated weathering trial was carried in the early 20th century to simulate the effect of colour fading (discolouration) caused by sun on the fabric [5]. Accelerated ageing tests arise from the need for rapid assessments of the durability and lifetime of the materials and the desire to predict their long-term behavior under natural conditions. 
In paints, the artificial ageing is usually photochemical (generated by ultraviolet or visible light), thermal (applying high temperatures or freeze-thawing cycles), due to moisture, and by the effect of salts (mainly sulfates and chlorides), ozone, nitric acid or carbon dioxide. In the recently published study by Izzo et al. [6], thermal, ozone and humidity treatments were performed on oil, acrylic and vinyl paints. After the treatment, physical changes were recorded, with a significant mass increase and a change of colouration in the samples, especially in acrylic and vinyl paints. Chemical changes were not registered, however. Cortea et al. [7] worked with five acrylic paints widely used in art, of yellow, red, purple and blue colours, manufactured by Liquitex ${ }^{\circledR}$ (Cincinnati, OH, USA). These were gradually aged under ultraviolet light for 50, 100 and $230 \mathrm{~h}$, and extreme conditions of temperature and humidity, reaching $-5{ }^{\circ} \mathrm{C}$ and $60{ }^{\circ} \mathrm{C}$ and a relative humidity (RH) of $40 \%$ and $60 \%$, every $24 \mathrm{~h}$. In order to monitor the physical changes produced in the samples, measurements of colour and Fourier transform infrared spectroscopy (FTIR) were performed.

Ageing tests and natural exposure tests led to similar changes on four kinds of typical marine coatings as recorded by Zhang et al. [8]. The gloss, surface morphology, coating impedance, and infrared spectra of the coatings were measured with scanning electron microscopy (SEM), electrochemical impedance spectroscopy (EIS), and FTIR, not obtaining significant differences between the accelerated and non-accelerated results. Similarly, Ecco et al. [9], working with coloured styrene-acrylic painted steel panels naturally aged in Trento (northern of Italy) and accelerated aged in the laboratory, suggested that one year of field exposure in Trento corresponds to approximately $250 \mathrm{~h}$ of exposition to UV-B lamps under laboratory conditions.

Carmona-Quiroga et al. [10] and Doehne and Price [11] recommended running natural and artificial weathering tests in parallel. Nevertheless, field exposure tests may last for several years before a reasonable conclusion can be drawn, and, for research and development purposes, there is often the need to obtain the outcomes in a shorter period of time. Hence, the reason for the wide acceptance of artificial ageing studies alone in the conservation practice, without resorting to a natural counterpart to compare the results obtained [5].

As part of a larger research project entitled "BioRemoGraf: Application of bioremediation to remove graffiti from cultural heritage and civil buildings" [12-14], the aims of the present study were to determine the changes that occur over time in the physical, chemical and structural properties of spray paints commonly used in graffiti [12], by characterizing the materials before and after being subjected to accelerated ageing trials. The findings will provide information about how graffiti paint ages, thus helping to improve strategies for the removal of graffiti from stonework. In addition, the most deleterious laboratory test, which produces the fastest and most intense artificial ageing of graffiti paint on this type of material, will be established. For this purpose, we used gravimetric analysis, digital images, reflectance colour measurements and infrared spectroscopy (FTIR) to evaluate the changes in a non-metallic (black) and a metallic (silver) spray paint applied to two types of igneous rock (granite and rhyolite ignimbrite) and a sedimentary rock (biocalcarenite) and subjected to widely employed artificial ageing tests involving exposure to salts $\left(\mathrm{NaCl}\right.$ and $\left.\mathrm{Na}_{2} \mathrm{SO}_{4}\right)$, freezing/thawing cycles and high humidity.

\section{Materials and Methods}

\subsection{Materials: Graffiti Spray Paint and Building Stone}

Aerosol spray paints are commonly used to produce graffiti because they can be quickly and easily applied to any type of substrate [12]. In this study, a black, non-metallic spray paint (Montana Colors Nitro 2G) and a silver, metallic spray paint (Montana Colors Hardcore 2) [15] were selected for testing. Black paint was chosen as graffitists and suppliers concur that it is the most popular type of paint used [12]. The silver paint was chosen because it is particularly difficult to eliminate. Removal of silver paint with laser (quite common [12], and one of the most sophisticated removal methods) leads to the appearance of an opaque film, which notably alters the appearance of the stone and scatters 
silver particles over the surface [13] and can also melt some minerals present in the stone (such as biotite) due to the high temperature reached during the process [12].

Three different types of stone were used as the substrates for applying the graffiti paints:

- Blanco Cristal granite (igneous rock) from Cadalso de los Vidrios (Madrid, Spain), a white leucogranite, heterogranular-panallatriomorphic medium-grained biotite adamellitic granite. The essential components of this granite are quartz (26\%), K-feldspar (29\%), plagioclases $(27.5 \%)$, biotite $(9 \%)$, muscovite $(2 \%)$ and chlorite $(4.5 \%)$ as an accessory mineral [16,17]. Granite is particularly common in Galicia (where this lithotype constitutes almost $50 \%$ of the geological substrate), northern Portugal, Brittany and Ireland. Many of the buildings and monuments in these areas are built from this material.

- Rhyolitic ignimbrite (igneous rock), extrusive or volcanic rock equivalent to granite from Central America. Its composition is very varied, consisting of a matrix based on silicates and Na-feldspar, K-feldspar and Ca-feldspar, with some pyroclastic products in the form of quartz, pumice and volcanic glass and some accessory mineral grains such as chlorite, sericite, hematite and leucoxene. It was used very extensively in prehispanic Mexican monuments, e.g., the Tiristán monuments (Quinceo, Michoacan) and a cosmogonic stone, which is on display in the Section of Archeology of the Michoacan State Museum.

- The stone of Puerto de Santa María (sedimentary rock) from Cádiz (Spain) is a calcarenite bio-esparithic or fossiliferous limestone (biocalcarenite) with a highly variable silica/calcium carbonate ratio, of colour ranging between greyish and yellowish. The texture is grainy, with fine to medium grain size, and a higher proportion of bioclasts and quartz grains [18,19]. This type of stone is found e.g., in the Cathedral of Seville and Cadiz (Andalusia, Spain). In the 17th century, this type of stone was considered the strongest in the area and was used for constructing pillars and columns and not as ornamental stone.

Eighty samples of granite of dimensions $4 \mathrm{~cm} \times 4 \mathrm{~cm} \times 1 \mathrm{~cm}, 20$ samples of ignimbrite of dimensions $2 \mathrm{~cm} \times 2 \mathrm{~cm} \times 1 \mathrm{~cm}$, and 20 samples of biocalcarenite of dimensions $3 \mathrm{~cm} \times 3 \mathrm{~cm} \times 1 \mathrm{~cm}$ were painted with either black non-metallic paint (half of them) or silver metallic paint (the other half). Forty of the granite samples were painted approximately one year before the study, while the other 40 were painted immediately before starting the study. The natural ageing of the graffiti was thus able to be considered a parameter under study. The types of samples and accelerated ageing tests used in the study are summarized in Table 1.

Table 1. Samples used for weathering tests: code, description and type of ageing test.

\begin{tabular}{|c|c|c|}
\hline Code & Description & Ageing Test * \\
\hline GNA & $\begin{array}{l}\text { Blanco Cristal granite with non-metallic (black) paint: } \\
\text { one year old }\end{array}$ & $\begin{array}{l}\text { Humidity }(3 ; 5) \text {, freeze-thawing }(10 ; 20), \\
\mathrm{NaCl} \text { and } \mathrm{Na}_{2} \mathrm{SO}_{4} \text { salts }(7 ; 14)\end{array}$ \\
\hline GNB & Blanco Cristal granite with non-metallic (black) paint & $\begin{array}{l}\text { Humidity }(3 ; 5) \text {, freeze-thawing }(10 ; 20), \\
\mathrm{NaCl} \text { and } \mathrm{Na}_{2} \mathrm{SO}_{4} \text { salts }(7 ; 14)\end{array}$ \\
\hline GPA & $\begin{array}{l}\text { Blanco Cristal granite with metallic (silver) paint: one } \\
\text { year old }\end{array}$ & $\begin{array}{l}\text { Humidity }(3 ; 5) \text {, freeze-thawing }(10 ; 20), \\
\mathrm{NaCl} \text { and } \mathrm{Na}_{2} \mathrm{SO}_{4} \text { salts }(7 ; 14)\end{array}$ \\
\hline GPB & Blanco Cristal granite with metallic (silver) paint & $\begin{array}{l}\text { Humidity }(3 ; 5) \text {, freeze-thawing }(10 ; 20), \\
\mathrm{NaCl} \text { and } \mathrm{Na}_{2} \mathrm{SO}_{4} \text { salts }(7 ; 14)\end{array}$ \\
\hline IN & Rhyolitic ignimbrite with non-metallic (black) paint & Humidity $(3 ; 5)$, freeze-thawing $(10 ; 20)$ \\
\hline IP & Rhyolitic ignimbrite with metallic (silver) paint & Humidity $(3 ; 5)$, freeze-thawing $(10 ; 20)$ \\
\hline $\mathrm{BCN}$ & $\begin{array}{l}\text { Biocalcarenite of Puerto de Santa María with } \\
\text { non-metallic (black) paint }\end{array}$ & Humidity $(3 ; 5)$, freeze-thawing $(10 ; 20)$ \\
\hline $\mathrm{BCP}$ & $\begin{array}{l}\text { Biocalcarenite of Puerto de Santa María with metallic } \\
\text { (silver) paint }\end{array}$ & Humidity $(3 ; 5)$, freeze-thawing $(10 ; 20)$ \\
\hline
\end{tabular}

* Five samples were used in each ageing trial, and the number of cycles for each ageing trial is shown in parentheses. 
The stone samples were painted outdoors. The cans of spray paint were shaken before use, according to the manufacturer's instructions [20]. The stone samples were sprayed three times with the paint to completely cover of the surface, maintaining a constant spray velocity and pressure, at a distance of approximately $15 \mathrm{~cm}$ between the samples and the can, which was held at an approximate angle of $45^{\circ}$, according to the American Standard ASTM D7089 [21].

\subsection{Ageing Trials}

\subsubsection{Humidity Cycles}

Forty painted stone specimens were used in the humidity ageing test (Table 1). Following ASTM standard D 870-02 [22], as modified by Bhargava et al. [23], the 40 specimens were placed in an oven at $38 \pm 1{ }^{\circ} \mathrm{C}$, in which a moist environment had been created by evaporation of deionized water contained in a tray located underneath the tray holding the sample. Samples were removed every $200 \mathrm{~h}$, i.e., one cycle of treatment, until a total of 5 cycles (1000 h) were completed.

\subsubsection{Freeze-Thawing Cycles}

For ageing using freeze-thawing cycles, the same type and number of specimens were used as in the previous treatment (Table 1). Following ASTM standard D 6944-03 [24], which was modified slightly to fit the devices available in the laboratory, the 40 specimens were placed in a freezer at $-10 \pm 1{ }^{\circ} \mathrm{C}$ for $16 \mathrm{~h}$ and then in an oven at a temperature of $64 \pm 2{ }^{\circ} \mathrm{C}$ for $8 \mathrm{~h}$. This treatment comprises one freeze-thawing cycle. The changes produced in the test specimens were analyzed after 10 and 20 cycles.

\subsection{3. $\mathrm{NaCl}$ and $\mathrm{Na}_{2} \mathrm{SO}_{4}$ Salt Cycles}

For ageing with soluble salts, only the granite samples (40 specimens of Blanco Cristal granite, i.e., 20 for each type of salt $\left[\mathrm{NaCl}\right.$ and $\left.\mathrm{Na}_{2} \mathrm{SO}_{4}\right]$ ) were used because of the greater resistance of this lithotype to salt. The samples of rhyolitic ignimbrite and biocalcarenite deteriorated quickly when in contact with the saline solution and thus would not act as good support for the graffiti paints, as the changes in the graffiti produced by the salts would not be able to be established. As in the two previous ageing treatments, half of the stone samples were painted with the black spray paint and the other half with the silver paint, at two different times: about one year before the start of the study and immediately before the start of the study (Table 1).

The salts selected for the tests were $\mathrm{Na}_{2} \mathrm{SO}_{4}$, which causes severe deterioration of rocks [25], and $\mathrm{NaCl}$, which affects the construction materials used in coastal areas in the study region. In both cases, the trials followed the RILEM (1978) standard [26], slightly modified by Sanmartín [27]. The treatment consisted of three steps, which form one treatment cycle:

- Full immersion of the test pieces in a $14 \%$ salt solution for $2 \mathrm{~h}$;

- Removal of the specimens from the solution and transfer to an oven at $40{ }^{\circ} \mathrm{C}$ for $16 \mathrm{~h}$;

- Removal of the test pieces from the oven and maintenance at room temperature for $3 \mathrm{~h}$ in a room that does not exceed $80 \%$ relative humidity $(\mathrm{RH})$.

A total of 14 cycles were completed. At the end of the 7th and 14th cycles, the stone samples were desalted in ultrapure water until the electrical conductivity in the wash water was less than $0.5 \mu \mathrm{S} \mathrm{cm}^{-1}$, and the changes were then determined.

\subsection{Analytical Techniques Used to Evaluate the Effects of the Accelerated Ageing}

\subsubsection{Characterization of the Physical Properties}

Gravimetric analysis was carried out. Measurement of the mass of the painted specimens was of particular interest because ageing treatments generally cause a change in this variable. The specimens 
were weighed on a laboratory precision balance (Denver Instruments, Denver, CO, USA) immediately before and after the accelerated ageing treatments were completed.

Physical and imaging techniques are used almost exclusively to evaluate the efficiency and effectiveness of graffiti removal methods [13]. Hence, in order to evaluate any physical changes visible to the naked eye, the painted specimens were photographed with a digital camera immediately before and after the corresponding ageing treatments, with the instrumentation described and following the methodology developed by Sanmartín et al. [17]. Thus, the samples were placed on a homogeneously illuminated measuring table and images were captured with a PixeLINK PL-A782 camera (Ottawa, ON, Canada) connected to a computer with the PixeLINK ${ }^{\circledR}$ program. In addition, at the beginning of treatment scanning electron microscopy (SEM) with X-ray microanalysis (EDS), JEOL JSM-6700 F (Tokyo, Japan) and Philips XL30 (Amsterdam, The Netherlands), working in both modes, secondary electrons (SE) and backscattered electrons (BSE), was applied to examine how was the contact between the graffiti paint and the stone support.

Finally, paint is susceptible to discolouration through pigment fading and to breakdown of polymer in the binder [13]. Characterization of colour in ageing studies of paint is therefore a key technique. Reflectance colour measurements were made with a portable spectrophotometer (Konica Minolta CM-700d, Tokyo, Japan) equipped with CM-S100w (SpectraMagicTM NX) software (Professional Edition, Tokyo, Japan), following the method developed by Prieto et al. [28] and carrying out the number of measurements corresponding to the target surface area (Section 2.1). Measurement conditions were as follows: Illuminant D65, observer $2^{\circ}$ and a $3 \mathrm{~mm}$ diameter target area. Colour measurements were analyzed by considering the CIELAB colour system (CIE, 1986), which represents each colour by means of three scalar parameters or the Cartesian coordinates: $L^{*}$, lightness or luminosity of colour, which varies from 0 (absolute black) to 100 (absolute white); $a^{*}$, associated with changes in redness-greenness (positive $a^{*}$ is red and negative $a^{*}$ is green); and $b^{*}$, associated with changes in yellowness-blueness (positive $b^{*}$ is yellow and negative $b^{*}$ is blue). Total colour changes were determined using the following equation: $\Delta E_{\mathrm{ab}}^{*}=\left(\Delta L^{* 2}+\Delta a^{* 2}+\Delta b^{* 2}\right)^{1 / 2}$, for the changes $(\Delta)$ in each parameter before and after the ageing treatment.

\subsubsection{Infrared Spectroscopy}

The chemical changes in the graffiti induced by the ageing treatments were characterized by infrared Fourier transform (FTIR) spectroscopy, by staff at the Center for Scientific and Technological Support to Research (CACTUS) (University of Santiago de Compostela, Spain). The spectra were obtained using a spectrophotometer (VARIAN FTIR 670, Palo Alto, CA, USA), in the spectral range of the medium (400-4000 $\mathrm{cm}^{-1}$ ) with a resolution of $4 \mathrm{~cm}^{-1}$. Approximately $0.001 \mathrm{~g}$ of paint was obtained by scraping the surface of the stone samples with a scalpel blade. Each paint sample was dispersed in $0.119 \mathrm{~g}$ of $\mathrm{KBr}$, with the aid of an agate mortar, to form a translucent pellet, which was analyzed by IR. The data were treated with OPUS software (Version 3.x, Cooperative Library Network of Berlin-Brandenburg (KOBV), Berlin, Germany) by constructing the spectra, locating the peaks and contrasting them with the spectra in our own and published reference databases.

\subsubsection{Statistical Analysis}

Data were tested to identify any significant differences in the graffiti painted on stone samples before and after the ageing tests (5th cycle for humidity, 20th cycle for freeze-thawing and 14th cycle for salts) by using ANOVA and a post hoc Tukey-b test. Differences were considered significant at $p \leq 0.05$. All statistical analyses were performed with SPSS (SPSS v22.0 for Windows, IBM, New York, NY, USA). 


\section{Results and Discussion}

\subsection{Characterization of Graffiti Paints}

Characterization of non-metallic (black) and metallic (silver) spray paints at the beginning of the study showed that, for the same amount applied, black paint added more weight to the stone samples than silver paint (data not shown). The black paint also provided more complete coverage, as shown by the digital images (Figure 1). In both cases, this may be due to the chemical composition of the paints, which was characterized by infrared spectroscopy. The IR spectra (see Section 3.4.) of the black graffiti revealed the following: A first band at $3432 \mathrm{~cm}^{-1}$ corresponding to the hydroxyl groups $(-\mathrm{OH})$, two peaks at $2928 \mathrm{~cm}^{-1}$ next to a small shoulder corresponding to the bond between carbon and hydrogen $(\mathrm{CH})$ assigned to the asymmetric tension of methyl group $\left(-\mathrm{CH}_{3}\right)$, followed by a peak at $1722 \mathrm{~cm}^{-1}$, due to the vibration of the carbonyl group $(C=0)$. A band at $1441 \mathrm{~cm}^{-1} \mathrm{was}^{-}$ caused by deformation of the $\mathrm{CH}_{2}$ within the bond $\left(-\mathrm{CH}_{2}-\mathrm{CO}-\right)$ and by the symmetrical stretching of the carboxylate group (-COO-) together with the vibration of the $\mathrm{C}-\mathrm{H}$ aliphatic group. A strong peak at $1018 \mathrm{~cm}^{-1}$ was assigned to the stretching mode of the $\mathrm{C}-\mathrm{O}$ group. The bands at $668 \mathrm{~cm}^{-1}$ and $465 \mathrm{~cm}^{-1}$ are associated with the vibrational mode of the Ti-O group, typical of modern paints, and the presence of metal oxides, respectively. The intense peak of the carbonyl group, together with the shape of the spectrum and the bands between 1300 and $800 \mathrm{~cm}^{-1}$ corresponding to the ether group, confirms the sample as a paint containing alkyd resins. The silver paint (see Section 3.4.) has some peaks in common with the black paint; however, the absence of the carbonyl group band together with the appearance of the characteristic polyethylene bands at $2922 \mathrm{~cm}^{-1}, 1455 \mathrm{~cm}^{-1}, 1382 \mathrm{~cm}^{-1}$ and $703 \mathrm{~cm}^{-1}$ confirm a predominance of polyethylene-type polymers in this type of metallic paint.
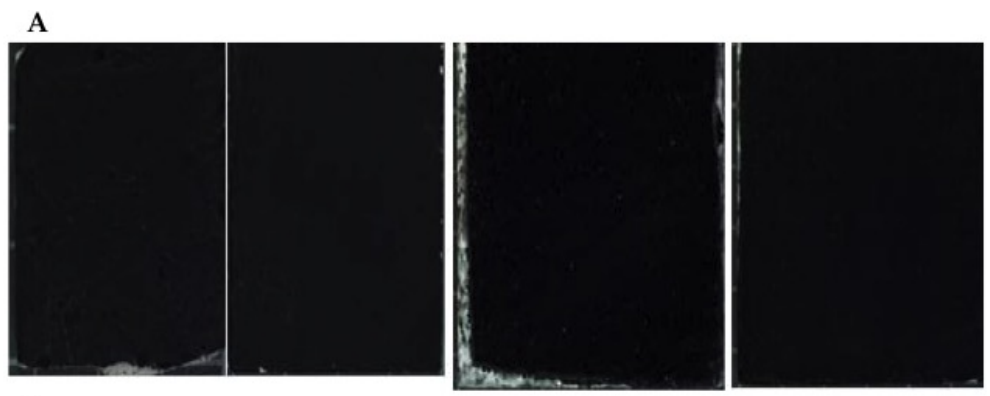

B

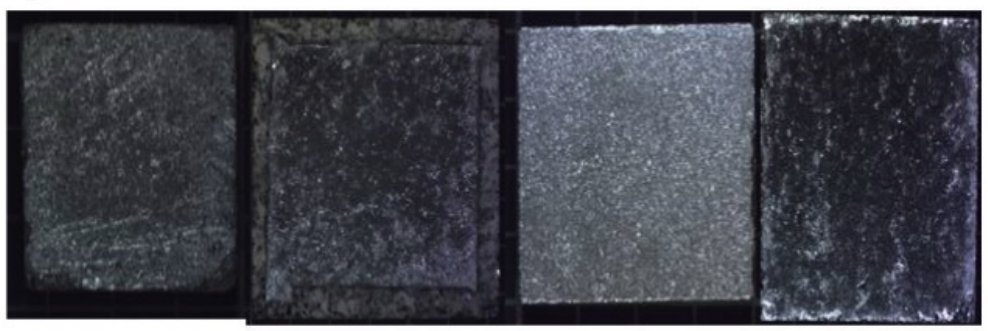

Figure 1. JPEG images of the painted stone samples at the beginning of the experiment. From left to right: (A) BCN, IN, GNA, GNB and (B) BCP, GPA, IP, GPB. The sample codes are shown in Table 1.

Observation of cross-sections of the graffiti-painted rock surfaces using SEM (Figure 2) also revealed the existence of different paint morphologies, especially pigment size and chemical composition. The back-scattered electron (BSE) detector revealed the black paint to be a continuous, homogeneous and fine-grained, with very low contrast film composed exclusively of carbon. In contrast, the composition of the silver paint has high BSE contrast with high concentrations of aluminum, pigment with a larger size and less dispersed in the matrix than carbon. 


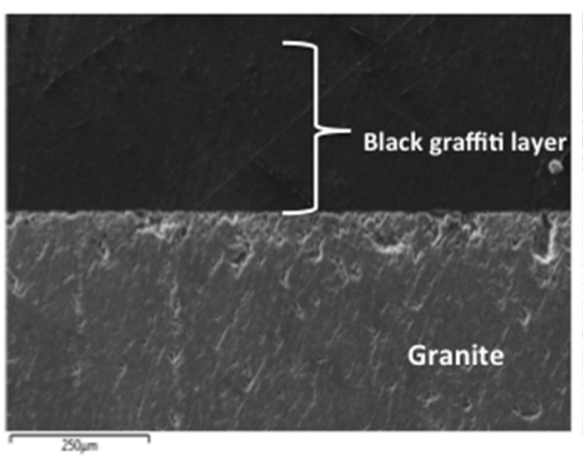

(a)

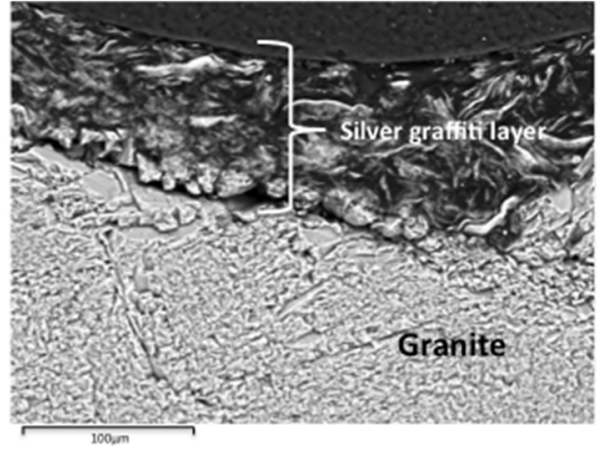

(b)

Figure 2. Cross-section micrographs of the granite surfaces painted obtained by SEM. (a) painted with the black graffiti paint (GNB); (b) painted with the silver graffiti paint (GPB). The sample codes are shown in Table 1.

Regarding the graffiti colour, the value of the $L^{*}$ parameter of the black paint was between 25.75 and 30.15 CIELAB units, indicating a very dark colour. Values of between -0.01 and -0.05 CIELAB units were obtained for the red-green component $\left(a^{*}\right)$ and of between -0.83 and -0.53 CIELAB units for the yellow-blue component $\left(b^{*}\right)$; in both cases, the proximity of the values to zero indicates that the samples were achromatic, although of the four colour components, the blue was slightly predominant. In the silver paint, the values of the parameter $\mathrm{L}^{*}$ were between 80.72 and 92.60 CIELAB units, indicating the high level of lightness or clarity of the samples; $\mathrm{a}^{*}$ values between -0.44 and -0.39 CIELAB units and $b^{*}$ values between -1.36 and -1.31 CIELAB units again indicate that the samples are achromatic, although somewhat less so than the previous samples; blue was again the main colour component.

\subsection{Ageing Trials: Humidity}

In the humidity ageing tests, the weight of the stone samples (Figure 3) generally increased with the number of treatment cycles. Only the rhyolitic ignimbrites (IP and IN) did not gain weight between the third and fifth cycles. This may be due to the smaller size of these specimens $(2 \mathrm{~cm} \times 2 \mathrm{~cm} \times 1 \mathrm{~cm}$, Section 2.1), which may have prevented them from absorbing more water after the third cycle. The increase in weight of the samples of silver-painted biocalcarenite (BCP) $(1.3 \%$ increase) was significantly greater than that of the other stone samples. It was followed by black-painted biocalcarenite (BCN), the painted rhyolitic ignimbrites (IP and IN) and the two granites painted one year earlier (GNA and GPA). Finally, the weight of the granites painted immediately before the start of the study (GNB and GPB) increased very slightly (by only $0.15 \%$ ) (a significantly lower increase than in the other samples). The increase in weight gain in the order granite $<$ ignimbrite $<$ biocalcarenite is probably due to the nature of the lithic substrate. The difference between the granite samples painted about a year apart was more notable, indicating that the age of graffiti enhances the effect of moisture absorption on the specimen. This would theoretically make the older graffiti more receptive to a chemical or biological cleaning treatment. Prompt removal of graffiti is usually recommended as it is generally considered that the paint becomes more difficult to remove over time [29]. However, studies involving the removal of graffiti from anti-graffiti surfaces are beginning to show that the effectiveness of the cleaning process may increase with the time that the graffiti has remained on the lithic substrate [30]. 


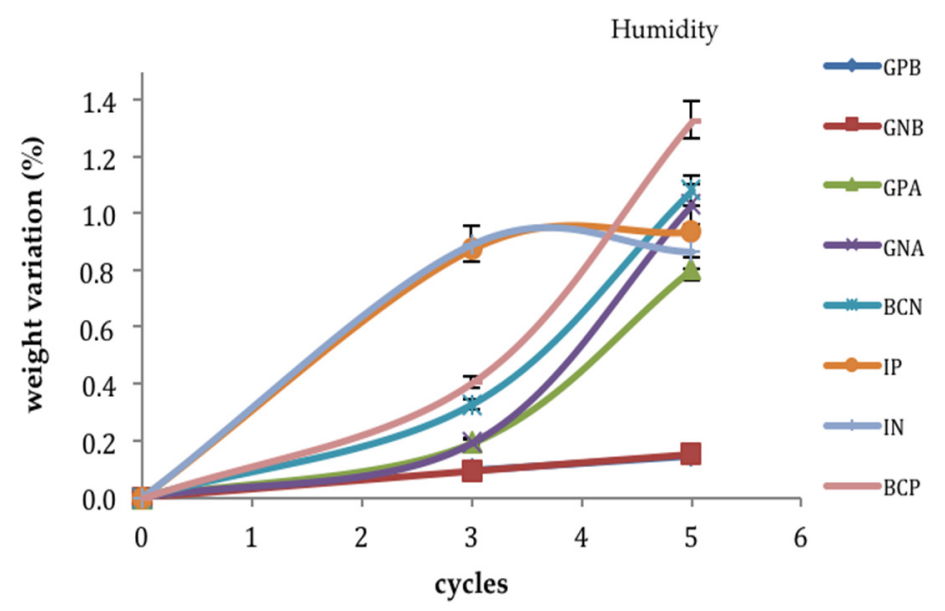

Figure 3. Variation in the weight of the specimens in humidity ageing tests. The sample codes are shown in Table 1.

The images obtained with the digital camera, for all the ageing tests, did not provide valuable information, as the visual appearance of the paint layers scarcely changed. The images are not shown in this or the following two sections.

Colour measurements (Figure 4) revealed change in the colour of all samples after exposure to the humidity. These changes were only significant and perceptible to the human eye (i.e., $\Delta E_{\mathrm{ab}}^{*}>1$ CIELAB unit [31]) in the black graffiti on biocalcarenite (BCN): $\Delta E^{*}{ }_{a b}=1.5$ CIELAB units after three cycles and $\Delta E^{*}{ }_{a b}=1.1$ CIELAB units after five cycles. This variation in colour mainly corresponds to a change in the $L^{*}$ parameter (data not shown) and may be due to the surface porosity of substrate $\mathrm{BC}$, which provided a larger contact surface between the lithic substrate and the paint, as well as voids and cracks that led to the paint being exposed to the moisture for longer and thus increasing the level of deterioration.

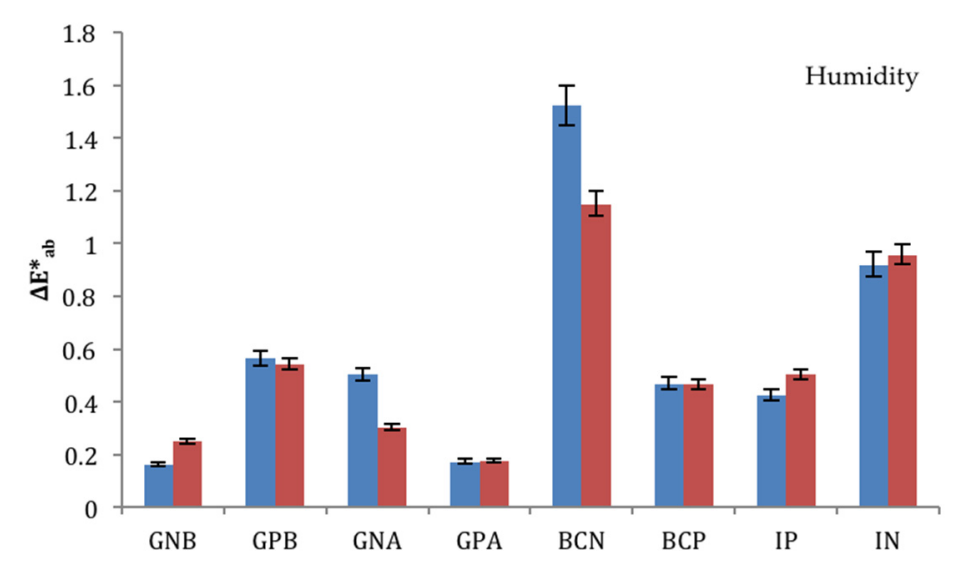

Figure 4. Total colour changes $\left(\Delta E_{\mathrm{ab}}^{*}\right)$ in the humidity ageing tests. Blue bars represent the differences after three cycles. Orange bars represent to the differences after five cycles. The sample codes are explained in Table 1.

Not all of the IR spectra obtained were informative and only those of interest to the study are presented. In the specimens subjected to the humidity cycles, no changes were observed between the start of the study and after the 3rd or 5th cycles (IR spectra not shown). 


\subsection{Ageing Trials: Freeze-Thawing}

In the accelerated ageing induced by freeze-thawing cycles, the weight changes were very variable and the corresponding weight variation graph was therefore not included.

The colour changes produced by the freeze-thawing ageing test were different from those obtained with the moisture treatment. In the case of freezing-thawing trials, all samples varied in colour, mainly in the same way as for humidity in the $L^{*}$ parameter (data not shown); however, only the changes in the silver-painted rhyolitic ignimbrite (IP) were detectable by the human eye (i.e., $\Delta E_{\mathrm{ab}}^{*}>1$ CIELAB unit [31]). Granite recently painted with the silver paint (GPB) and painted one year earlier with black paint (GNA) showed smaller changes in colour, with $\Delta E_{\mathrm{ab}}^{*}$ values of 0.3 and 0.4 CIELAB units. Although the $\Delta E^{*}$ ab value was only higher than 1 for sample IP, $\Delta E^{*}{ }_{a b}$ values higher than 0.73 CIELAB units were obtained for samples of rhyolitic ignimbrites painted with the black paint (IN) and the biocalcarenite painted with black (BCN) and silver paint (BCP) (Figure 5). This lower limit of perception has been applied in some studies [32,33]. Two different groups of stone/graffiti samples were distinguished on the basis of the statistical analysis, one comprising BCN, BCP, IP and $\mathrm{IN}$, and the other comprising GNB, GPB, GNA and GPA. Therefore, the same explanation as given for the humidity ageing test results is plausible. When graffiti are applied to stone with holes, cavities and irregularities as found in rhyolite and calcarenite, which are more porous than the smoother granites, water absorption is favoured by the increased time of exposure.

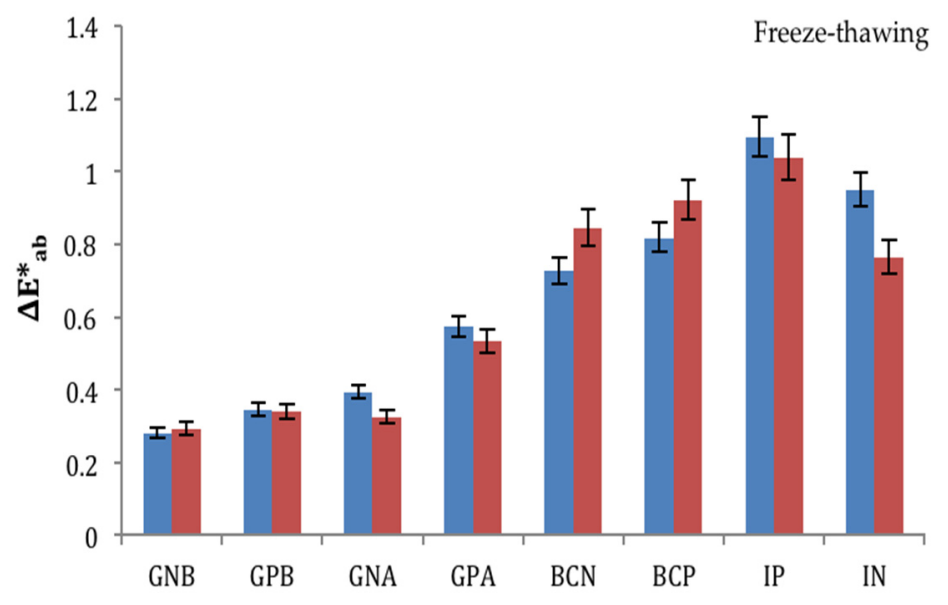

Figure 5. Total colour changes $\left(\Delta E^{*}{ }_{\mathrm{ab}}\right)$ in the accelerated ageing induced by freeze-thawing cycles. Blue bars represent the differences after 10 cycles. Orange bars represent the differences after 20 cycles. The sample codes are explained in Table 1.

Only changes in the infrared spectra of black paint on biocalcarenite were observed. Figure 6 shows the infrared spectra from the freeze-thawing treatment where the transmittance of the peaks decreased with the cycles. Bands of the carbonyl group and those associated with alkyd resins did not decrease in comparison with other bands in the same spectra associated with a possible degradation of the paints. Hence, a possible explanation is that infrared spectra were registered on each of the three occasions with a slightly different amount of sample (Section 2.3.2). 


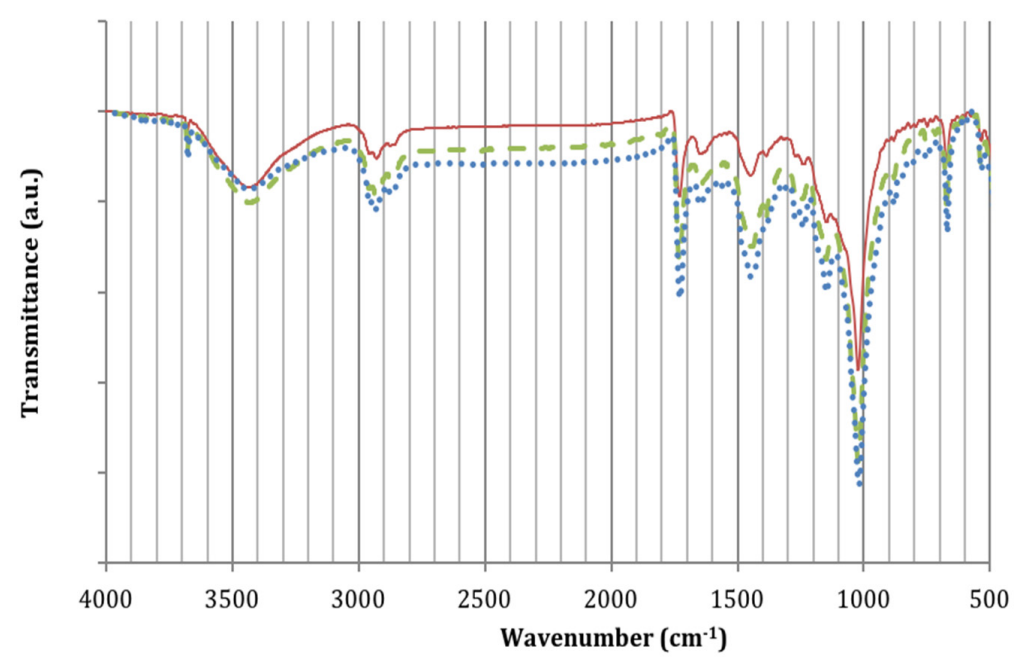

Figure 6. Infrared spectra (4000-400 $\mathrm{cm}^{-1}$ ) of non-metallic (black) graffiti on biocalcarenite after accelerated ageing induced by freeze-thawing cycles. The dotted blue line of the spectrum corresponds to the beginning of the treatment, the dashed grey line to the 10th cycle and the continuous orange line to the 20th cycle.

\subsection{Ageing Trials: $\mathrm{NaCl}$ and $\mathrm{Na}_{2} \mathrm{SO}_{4}$ Salts}

Ageing tests with the salts $\mathrm{NaCl}$ and $\mathrm{Na}_{2} \mathrm{SO}_{4}$ cycles were only carried out with the granite specimens. The results showed that, after 14 cycles of $\mathrm{NaCl}$ treatment, weight loss was greatest in the granite samples recently painted with black graffiti (Figure 7). Indeed, the weight of the granite samples treated with salts was only significantly lower in the samples recently painted with black graffiti and treated with $\mathrm{NaCl}$, and also to a lesser extent in the samples recently and previously painted with black graffiti and treated with $\mathrm{Na}_{2} \mathrm{SO}_{4}$.

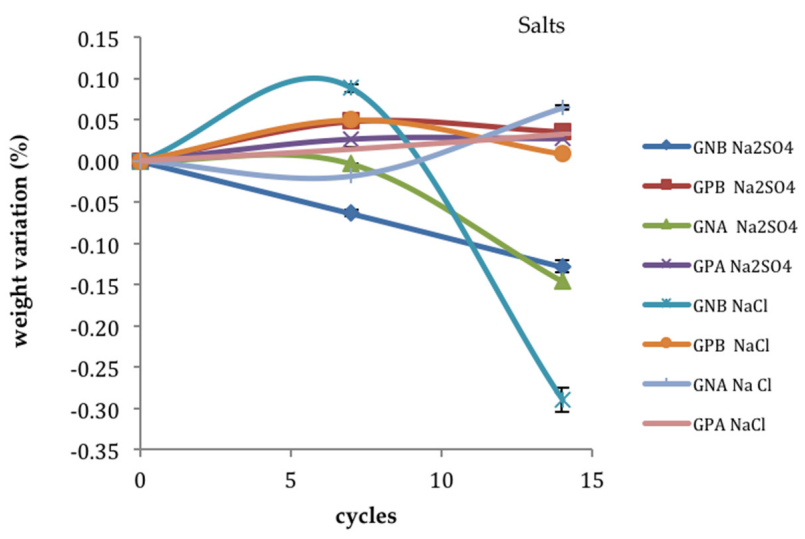

Figure 7. Variations in the weight of the stone samples in the accelerated ageing induced by $\mathrm{NaCl}$ and $\mathrm{Na}_{2} \mathrm{SO}_{4}$ salt cycles. The sample codes are explained in Table 1.

Sodium sulphate usually forms the most voluminous efflorescences (saline deposits) on stone surfaces. Alkyd-based paints, such as the black graffiti paint used in this study, display some capacity to cover efflorescences, which could explain the lower weight loss. These variations (decrease in weight) were not, however, elevated, as they did not exceed $0.3 \%$ of weight loss, in which we must also include that amount associated with the loss of lithic material. The weight of the other samples increased slightly after the treatment, by between $0.01 \%$ and $0.05 \%$. This result may indicate that the silver graffiti paint is not affected at the level of loss of material due to the soluble salts used, possibly because the polymers that are abundant in this type of paint are chemically inert and impermeable to 
water (unlike the alkyd and polyester resins in the black paint). Paints based on alkyd resins can be saponified (resulting in peeling or destruction of paint) due to the alkaline conditions caused by the presence of moisture and the alkaline salts used $\left(\mathrm{NaCl}\right.$ and $\left.\mathrm{Na}_{2} \mathrm{SO}_{4}\right)$. Therefore, it can be concluded that the salt-induced ageing mainly affected the non-metallic (black) paint and did not have an important effect on the metallic (silver) paint. On the other hand, both salts cause a similar weight loss of the paints, and neither caused a higher level of deterioration than the other.

Ageing trials with salt provoked the greatest changes in the total colour $\left(\Delta E_{\mathrm{ab}}^{*}\right)$ of the specimens (Figures 8 and 9). In almost all cases and after the 7th treatment cycle, the value exceeded 1 CIELAB unit [31], and, for the case of $\mathrm{Na}_{2} \mathrm{SO}_{4}$, it exceeded 3 CIELAB units, indicating colour differences that are easily perceived by the human eye [31-33]. This shows that although the weight measurement (Figure 7) did not allow the deterioration produced by the two salts to be distinguished, this was achieved using colour measurements. After 14 cycles of $\mathrm{NaCl}$ treatment (Figure 8), the greatest differences were observed in the samples painted one year before the start of the study (GNA and GPA) and in the samples recently painted with silver paint (GPB), which reached a value of $\Delta E^{*}{ }_{\mathrm{ab}}=1.6$ CIELAB units, significantly higher than that obtained by GNB. This shows the greater vulnerability of older paints to weathering agents, and, as discussed above, may facilitate the cleaning of older graffiti.

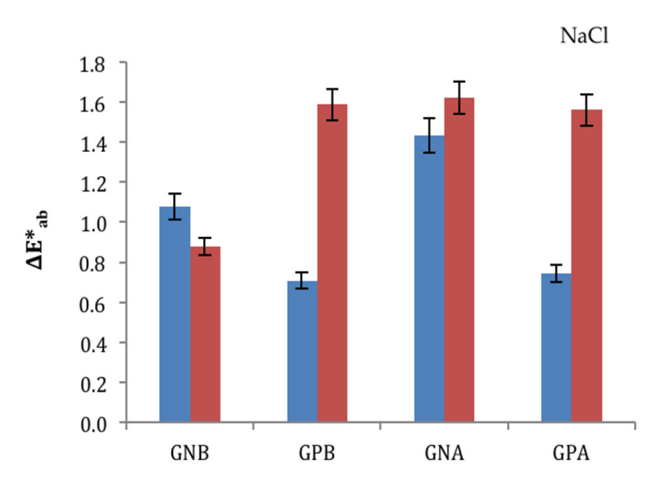

Figure 8. Total colour changes $\left(\Delta E^{*}\right.$ ab $)$ in the accelerated ageing induced by $\mathrm{NaCl}$ and $\mathrm{Na}_{2} \mathrm{SO}_{4}$ salt cycles. Blue bars represent the differences after seven cycles. Orange bars represent the differences after 14 cycles. The sample codes are shown in Table 1.

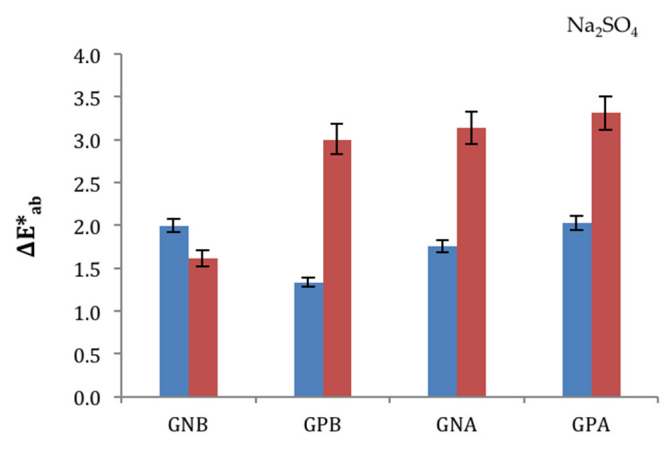

Figure 9. Total colour changes $\left(\Delta E_{\mathrm{ab}}^{*}\right)$ due to accelerated ageing induced by $\mathrm{NaCl}$ and $\mathrm{Na}_{2} \mathrm{SO}_{4}$ salt cycles. Blue bars represent the differences after seven cycles. Orange bars represent the differences after 14 cycles. The sample codes are explained in Table 1.

For $\mathrm{Na}_{2} \mathrm{SO}_{4}$ (Figure 9), colour changes in all stone/graffiti samples (GNB, GPB, GNA and GPA) were perceptible after the 7 th cycle $\left(\Delta E^{*}{ }_{\mathrm{ab}}>1\right.$ CIELAB unit). After 14 cycles, the granite samples painted one year before the start of the study began to show a notable change in colour, of more than three CIELAB units, which again shows that the age of the paint affects the changes produced by the weathering agents. 
The infrared spectra of graffiti applied to granite samples one year before the start of the study and immediately before the study were different, revealing differences in the level of degradation of the older relative to the new graffiti (data not shown). The differences observed in the initial IR spectra were maintained during the salt-induced ageing treatment. Other differences were also observed in relation to the salt exposure. We were not able to distinguish clear patterns of change in relation to the age of the graffiti, possibly because of the substantial deterioration of the stone samples. Further studies will be carried out with the aim of clarifying this point. The results discussed in the present study therefore only correspond to the patterns common to both types of graffiti (old and new) due to attack by salts, and only the graphs for the recently painted graffiti are shown.

The infrared graphs corresponding to the salt treatment (Figures 10-13) show that the effect of both salts on black graffiti paint was very different from the effect on silver graffiti paint. For black paint, a similar effect to that observed with freeze-thawing cycles (Figure 6) was found, with both sodium chloride (Figure 10) and sodium sulfate (Figure 11). The intensity of the bands decreased. However, as referred to before, it may not be associated with degradation of the paints.

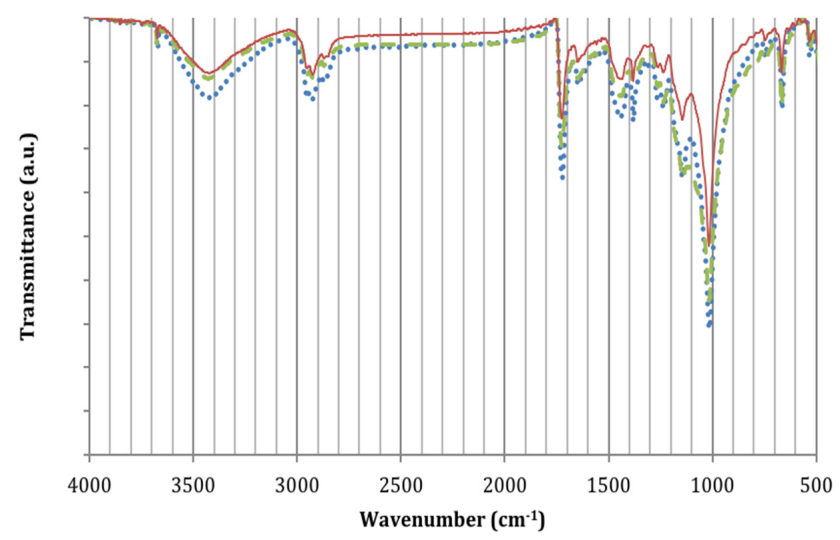

Figure 10. Infrared spectra $\left(4000-400 \mathrm{~cm}^{-1}\right)$ of non-metallic (black) graffiti on granite after accelerated ageing induced by $\mathrm{NaCl}$ salt cycles. The dotted blue line of the spectrum corresponds to the beginning of the treatment, the dashed grey line to the 7 th cycle and the continuous orange line to the 14th cycle.

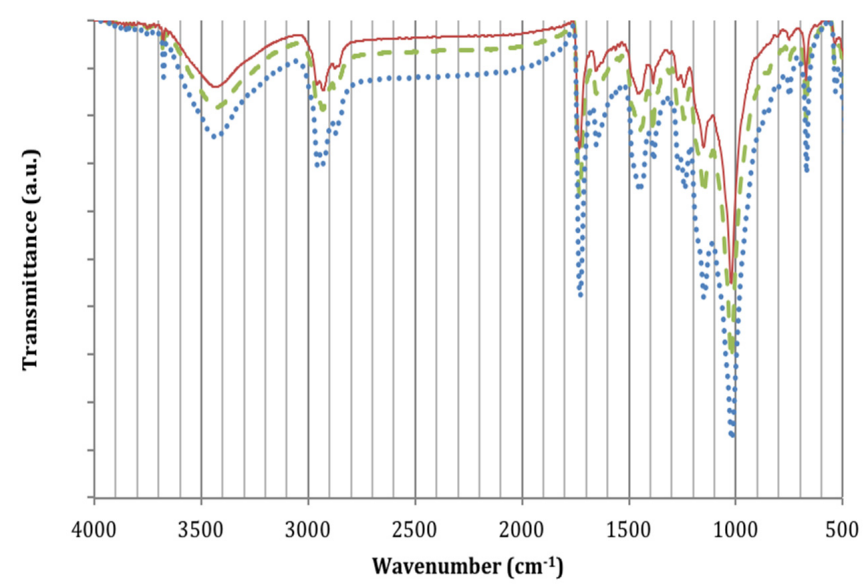

Figure 11. Infrared spectra $\left(4000-400 \mathrm{~cm}^{-1}\right)$ of non-metallic (black) graffiti on granite after accelerated ageing induced by $\mathrm{Na}_{2} \mathrm{SO}_{4}$ salt cycles. The dotted blue line of the spectrum corresponds to the beginning of the treatment, the dashed grey line to the 7 th cycle and the continuous orange line to the 14 th cycle. 


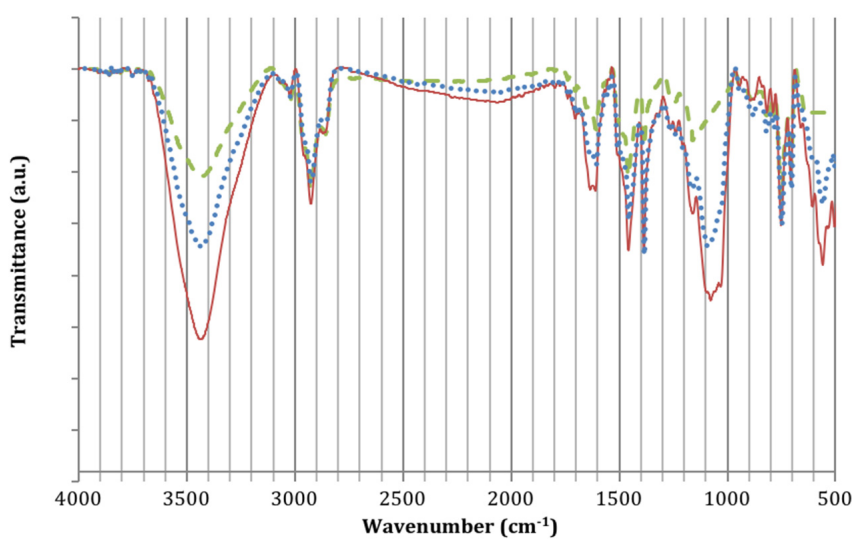

Figure 12. Infrared spectra $\left(4000-400 \mathrm{~cm}^{-1}\right)$ of metallic (silver) graffiti on granite in the accelerated ageing induced by $\mathrm{NaCl}$ salt cycles. The dotted blue line of the spectrum corresponds to the beginning of the treatment, the dashed grey line to the 7th cycle and the continuous orange line to the 14th cycle.

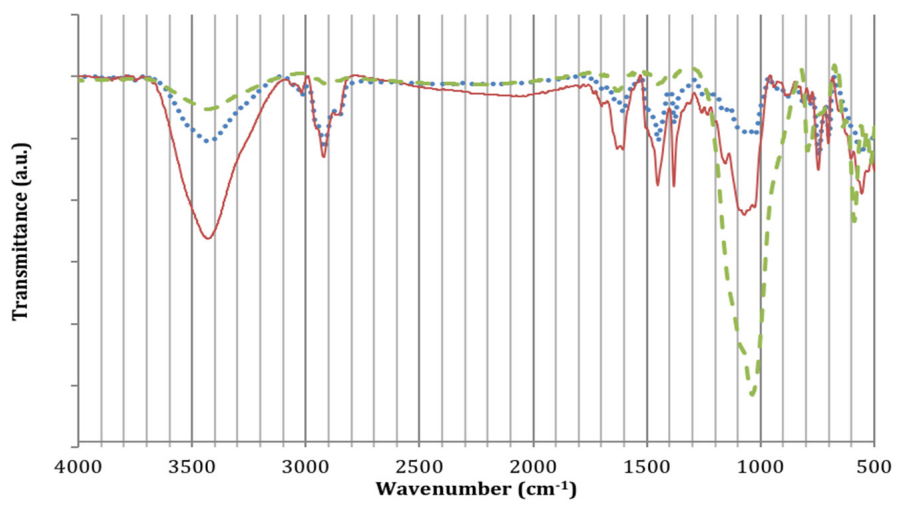

Figure 13. Infrared spectra $\left(4000-400 \mathrm{~cm}^{-1}\right)$ of metallic (silver) graffiti on granite in the accelerated ageing induced by $\mathrm{Na}_{2} \mathrm{SO}_{4}$ salt cycles. The dotted blue line of the spectrum corresponds to the beginning of the treatment, the dashed grey line to the 7 th cycle and the continuous orange line to the 14th cycle.

$\mathrm{NaCl}$ is mostly transparent to infrared radiation (due to it being used like $\mathrm{KBr}$ to prepare pellets), and only between $800-400 \mathrm{~cm}^{-1}$ does the halite spectrum exhibit a broad band [34]. It does not seem to appear in the black graffiti paint (Figure 10), indicating that no $\mathrm{NaCl}$ residues remained on the specimens after they were washed with ultrapure water. This is consistent with the data provided by the weight measurement (Figure 7), which indicated that although the sulphate salt probably remained as a sub-efflorescence in the black paint, the chloride salt had been removed. For silver paint, the chloride salt (Figure 12) yielded more intense bands with each treatment cycle. However, some bands, such as bands at 3500-3400 $\mathrm{cm}^{-1}$ and $1700-1600 \mathrm{~cm}^{-1}$, are simply associated with a greater presence of water (humidity) in the samples.

Bands associated with sodium sulphate $\left(\mathrm{NaSO}_{4}\right)$ are found at $616 \mathrm{~cm}^{-1}, 638 \mathrm{~cm}^{-1}, 1123 \mathrm{~cm}^{-1}$, $1637 \mathrm{~cm}^{-1}, 2111 \mathrm{~cm}^{-1}, 2250 \mathrm{~cm}^{-1}$ and $3418 \mathrm{~cm}^{-1}$ [35], and the peak observed in the frequency range $600-500 \mathrm{~cm}^{-1}$ on the silver paint (Figure 13) could belong to the presence of sulphates, since the bands appeared below $700 \mathrm{~cm}^{-1}$ are assigned to the symmetric and asymmetric bending of $\mathrm{SO}_{4}{ }^{2-}$ groups [36]. However, they probably belong to silicates from granite, whose bands appear mainly in the $450-730 \mathrm{~cm}^{-1}$ and $1200-800 \mathrm{~cm}^{-1}$ regions [36].

Therefore, it can be concluded that $\mathrm{Na}_{2} \mathrm{SO}_{4}$ was the most damaging salt to both types of graffiti paints, though certainly graffiti coatings' degradation cannot be inferred from the infrared spectra. 
Finally, anti-graffiti protective coatings have been subjected to weathering tests in many studies. This is the first study to follow the changes in graffiti paints with a series of accelerated ageing trials. An interesting next step in the research would be combining studies in ageing of graffiti barrier coatings (anti-graffiti) and graffiti paints. At present, protective approaches against graffiti employing anti-graffiti coatings (which require resistance to wear abrasion) are becoming increasingly transparent, hydrophobic, and superhydrophobic and even oleophobic coatings, supporting a certain level of mechanical abrasion. However, despite significant progress, combining transparency with mechanical abrasion, resistance remains very challenging and is not described frequently in the literature. Furthermore, one of the main breakthroughs to achieve is to apply anti-graffiti over large areas commonly encountered for graffiti prevention, i.e., public transport vehicle windows, walls, or building windows, to name a few ([37], and references therein).

\section{Conclusions}

Characterization of graffiti spray paints revealed that non-metallic (black) paint is very different from metallic (silver) paint. Silver paint contains alkyd resins and aluminum in the pigmentary composition, while black paint predominantly contains polyethylene-type polymers and carbon black pigments. The black paint is much darker than the silver paint. The black paint is heavier and provides more complete coverage of the stone samples than provided by the silver paint.

In the humidity ageing tests, the weight of all specimens increased and the colour was modified; however, in the granite samples, this was only due to changes in the paint and not to changes in the substrate. These changes increased with the age of graffiti, which therefore increased the effect of moisture on the sample. This finding suggests that chemical or biological cleaning may be more effective for older graffiti than for recently painted graffiti.

In the accelerated ageing induced by freeze-thawing cycles, the age of graffiti caused an increase in the effect of treatment on the sample, although to a lesser extent than in the moisture-treated samples.

The ageing induced by $\mathrm{NaCl}$ and, in particular $\mathrm{Na}_{2} \mathrm{SO}_{4}$, yielded the most severe, faster and informative artificial ageing of both black and silver paints, including chemical changes. In this work, only granite was taken into consideration so whether this conclusion is valid also for other stones remains to be demonstrated. In this treatment, the age of the paint clearly affected the degree of damage, thus demonstrating the greater vulnerability of older paints to weathering agents.

Regarding the evaluation techniques used, colour measurement and infrared spectroscopy provided the most information. The digital images were not informative.

The samples considered in this study will be used in a future study of the microbially-induced removal of graffiti from construction materials.

Acknowledgments: The authors are grateful to Lucía Naveiro Seijo (University of Santiago de Compostela, Spain), who carried out her degree research on this subject within the BioRemoGraf project. This work was partly financed through grant GRC2014/028 (Xunta de Galicia). Patricia Sanmartín is currently financially supported by a postdoctoral contract within the framework of the 2011-2015 Galician Plan for Research, Innovation and Growth, Plan I2C, Modality B (2016 Call) with the project: “Light4Heritage: Lighting-based strategies to control biological colonization in the built heritage (2016-PG011)".

Author Contributions: Francesca Cappitelli first proposed the idea on which the BioRemoGraf project is based. Patricia Sanmartín conceived, designed and performed the experiments; Patricia Sanmartín analysed the data; Patricia Sanmartín and Francesca Cappitelli wrote the paper.

Conflicts of Interest: The authors declare no conflict of interest.

\section{References}

1. A Concelleira de Servizos Condena os Actos Vandálicos e Pide Responsabilidade Aos Traballadores do Servizo de Limpeza (In Galician). Available online: http://santiagodecompostela.gal (accessed on 27 October 2017).

2. Rabea, A.M.; Mirabedini, S.M.; Mohseni, M. Investigating the surface properties of polyurethane based anti-graffiti coating against UV exposure. J. Appl. Polym. Sci. 2012, 124, 3082-3091. [CrossRef] 
3. Carmona-Quiroga, P.M.; Blanco-Varela, M.T.; Martínez-Ramírez, S. Freeze-Thaw and UV Resistance in Building Stone Coated with Two Permanent Anti-graffiti Treatments. In Engineering Geology for Society and Territory; Lollino, G., Giordan, D., Eds.; Springer: Cham, Switzerland, 2015; Volume 8, pp. 531-534.

4. Carmona-Quiroga, P.M.; Jacobs, R.M.J.; Viles, H.A. Weathering of two anti-graffiti protective coatings on concrete paving slabs. Coatings 2017, 7, 1. [CrossRef]

5. Feller, R.L. Accelerated Aging: Photochemical and Thermal Aspects; Getty Conservation Institute: Los Angeles, CA, USA, 1994.

6. Izzo, F.C.; Balliana, E.; Pinton, F.; Zendri, E. A preliminary study of the composition of commercial oil, acrylic and vinyl paints and their behaviour after accelerated ageing conditions. Conserv. Sci. Cult. Herit. 2014, 14, 353-369.

7. Cortea, I.M.; Radvan, A.; Vasiliu, C.; Puscas, N. Preliminary results of accelerated ageing tests on acrylic art paints. Univ. Politeh. Buchar. Sci. Bull. Ser. 2014, 76, 215-222.

8. Zhang, H.; Dun, Y.; Tang, Y.; Zuo, Y.; Zhao, X. Correlation between natural exposure and artificial ageing test for typical marine coating systems. J. Appl. Polym. Sci. 2016, 133, 43893. [CrossRef]

9. Ecco, L.G.; Rossi, S.; Fedel, M.; Deflorian, F. Color variation of electrophoretic styrene-acrylic paints under field and accelerated ultraviolet exposure. Mater. Des. 2017, 116, 554-564. [CrossRef]

10. Carmona-Quiroga, P.M.; Jacobs, R.M.J.; Martínez-Ramírez, S.; Viles, H.A. Durability of anti-graffiti coatings on stone: Natural vs. accelerated weathering. PLoS ONE 2017, 12, e0172347. [CrossRef] [PubMed]

11. Doehne, E.; Price, C.A. Stone Conservation. In An Overview of Current Research, 2nd ed.; Getty Publications: Los Angeles, CA, USA, 2010.

12. Sanmartín, P.; Cappitelli, F.; Mitchell, R. Current methods of graffiti removal: A review. Constr. Build. Mater. 2014, 71, 363-374. [CrossRef]

13. Sanmartín, P.; Mitchell, R.; Cappitelli, F. Evaluation of Cleaning Methods for Graffiti Removal. In Urban Pollution and Changes to Materials and Building Surfaces; Brimblecombe, P., Ed.; Imperial College Press: London, UK, 2016; pp. 291-312.

14. Sanmartín, P.; DeAraujo, A.; Vasanthakumar, A.; Mitchell, R. Feasibility study involving the search for natural strains of microorganisms capable of degrading graffiti from heritage materials. Int. Biodeterior. Biodegr. 2015, 103, 186-190. [CrossRef]

15. Montana Colors ${ }^{\circledR}$. Available online: http://www.montanacolors.com (accessed on 27 October 2017).

16. Sanmartín, P.; Silva, B.; Prieto, B. Effect of surface finish on roughness, color and gloss of ornamental granites. J. Mater. Civ. Eng. 2011, 23, 1239-1248. [CrossRef]

17. Sanmartín, P.; Chorro, E.; Vázquez-Nion, D.; Martínez-Verdú, F.M.; Prieto, B. Conversion of a digital camera into a non-contact colorimeter for use in stone cultural heritage: The application case to Spanish granites. Measurement 2014, 56, 194-202. [CrossRef]

18. Esbert, R.M.; Ordaz, J.; Alonso, F.J.; Ruiz De Argandoña, V.G.; Montoto, M.; Marcos, R.; Valdeón, L. Petrophysical caracterization and weatherability of the stones of the Seville Cathedral. Mater. Constr. 1988, 38, 5-23. [CrossRef]

19. Sanmartín, P.; Rivas, T.; De los Santos, D.M.; Silva, B.; Mosquera, M.J. Effectiveness of a new water-repellent and consolidant nanomaterial applied to a biocalcareous stone. In Proceedings of the 11th International Congress on Deterioration and Conservation of Stone, Torun, Polonia, 15-20 September 2008; Volume II, pp. 1045-1054.

20. Giacomucci, L.; Toja, F.; Sanmartín, P.; Toniolo, L.; Prieto, B.; Villa, F.; Cappitelli, F. Degradation of nitrocellulose-based paint by D. desulfuricans ATCC 13541. Biodegradation 2012, 23, 705-716. [CrossRef] [PubMed]

21. ASTM D7089 Determination of the Effectiveness of Anti-Graffiti Coating for Use on Concrete, Masonry and Natural Stone Surfaces by Pressure Washing; American Society for Testing and Materials: West Conshohocken, PA, USA, 2006.

22. ASTM D 870-02 Standard Practice for Testing Water Resistance of Coatings Using Water Immersion, Annual Book of ASTM Standard; American Society for Testing and Materials: West Conshohocken, PA, USA, 2002.

23. Bhargava, S.; Kubota, M.; Lewis, R.; Advani, S.; Prasad, A.; Deitzel, J. Ultraviolet, water, and thermal aging studies of a waterborne polyurethane elastomer-based high reflectivity coating. Prog. Org. Coat. 2015, 79, 75-82. [CrossRef] 
24. ASTM D 6944-03 Standard Test Method for Resistance for Cured Coatings to Thermal Cycling, Annual Book of ASTM Standard; American Society for Testing and Materials: West Conshohocken, PA, USA, 2003.

25. Shahidzadeh-Bonn, N.; Desarnaud, J.; Bertrand, F.; Chateau, X.; Bonn, D. Damage in porous media due to salt crystallization. Phys. Rev. 2010, E81, 0066110. [CrossRef] [PubMed]

26. Reunion Internationale des Laboratoires d'Essais et de Recherche sur Les Materiaux et Les Constructions (R.I.L.E.M.) Paris. Crystallization Test by Total Inmersion (Test V.1). Crystallization Test by Partial Inmersion (Test V.2). In Proceedings of the International Symposium on Deterioration and Conservation of Stone Monuments (UNESCO-RILEM), Paris, France, 5-9 June 1978.

27. Sanmartín, P. Evaluación de dos Tratamientos Consolidantes Aplicados a Granitos y Calcarenitas, Work Submitted for Obtain the Research Sufficiency Diploma; University of Santiago de Compostela: Santiago, Spain, 2007; p. 103. (In Spanish)

28. Prieto, B.; Sanmartín, P.; Silva, B.; Martinez-Verdú, F. Measuring the color of granite rocks. A proposed procedure. Color Res. Appl. 2010, 35, 368-375. [CrossRef]

29. Removing Graffiti from Historic Properties. Available online: http://www.mass.gov/eea/docs/dcr/ stewardship/rmp/bmps/graffiti-removal.pdf (accessed on 27 October 2017).

30. Pozo-Antonio, J.S.; Rivas, T.; Jacobs, R.M.J.; Viles, H.A.; Carmona-Quiroga, P.M. Effectiveness of commercial anti-graffiti treatments in two granites of different texture and mineralogy. Prog. Org. Coat. Submitted.

31. Wyszecki, G.; Stiles, W.S. Color Science. Concepts and Methods. Quantitative Data and Formulae; Wiley: New York, NY, USA, 1982.

32. Völz, H.G. Industrial Color Testing; Wiley VCH: Weinheim, Germany, 2001.

33. Berns, R.S. Billmeyer and Saltzman's Principles of Color Technology, 3rd ed.; John Wiley and Sons: New York, NY, USA, 2000.

34. Sodium Chloride (NaCl). Available online: https://www.crystran.co.uk/optical-materials/sodiumchloride-nacl (accessed on 27 October 2017).

35. Periasamy, A.; Muruganand, S.; Palaniswamy, M. Vibrational studies of $\mathrm{Na}_{2} \mathrm{SO}_{4}, \mathrm{~K}_{2} \mathrm{SO}_{4}, \mathrm{NaHSO}_{4}$ and $\mathrm{KHSO}_{4}$ crystals. Rasayan J. Chem. 2009, 2, 981-989.

36. Socrates, G. Infrared and Raman Characteristic Group Frequencies, Tables and Charts; John Wiley and Sons, Ltd.: New York, NY, USA, 2004.

37. Bayer, I.S. On the durability and wear resistance of transparent superhydrophobic coatings. Coatings 2017, 7, 12. [CrossRef] 